\title{
Editorial: C.R., the new Editor-in-Chief of C.R.
}

\author{
Conly L. Rieder
}

Published online: 9 January 2013

(C) Springer Science+Business Media Dordrecht 2013

After 20 years at the helm, the original founding member and Editor-in-Chief of Chromosome Research, Professor Herbert Macgregor, has retired from the journal. After 18 months as Herbert's Editor-in-Chief in training, which involved $>5,000$ e-mails, many hours of Skype, as well as several meetings with associate editors, members of our Editorial Advisory Board, and Springer, I'm as ready as I'll ever be for the exciting challenge of editing the journal.

Similar to a child born into a military family, where sudden location changes are inevitable, the journal's development has been anything but uneventful: since its inception in 1992, it has been owned and managed by four different publishers starting with Rapid Communications of Oxford, then moving in 1996 to Rapid Science Publishers (Thomson Science), which was acquired by Kluwer Academic Publishers in 1998 before it merged in 2004 with Springer Verlag to form Springer Science+Business Media (where the journal currently resides). During this same 20-year period, the mechanics of scientific publishing changed from the snail mail submission of multiple hardcopies and

Responsible Editor: Conly L. Rieder

C. L. Rieder $(\bowtie)$

Marine Biology Laboratory,

Woods Hole, MA, USA

e-mail: conlyrieder@hotmail.com printed silver-halide photographic plates, which took a minimum of several months to review, to an efficient online submission and review system and subsequent rapid online publication. At the same time, the rapid growth of the world wide web has enabled new models for scientific publishing, and in the past 10 years, the open access (OA) model has gained momentum which has meant that progressively more journals have appeared in the field competing for good chromosome-related papers. I mention these changes to illustrate that Herbert Macgregor has not simply been the Editor-in-Chief of Chromosome Research for the past 20 years, but also a concerned "parent" whose patience, guidance, and tutelage have ensured that Chromosome Research has matured into the respected international scientific publishing forum that it is today.

In his first editorial (vol. 1, \#1, page 3; May 2003) Herbert and his co-founders Pat Heslop-Harrison and Michael Schmid set out to launch a "fresh journal that was manifestly for chromosomologists, a journal that offered quick, no-fuss communication at the highest possible standard that was widely affordable." They also defined its scope to be "wide, ranging from microbes to humans and higher plants. Basically, if your science is about chromosomes or any of the front line technologies that feature in chromosome research, then we want to publish it." I am pleased to confirm that all aspects of their objective have become a reality. 
As Editor-in-Chief, my primary aim will be to continue to attract high-quality papers on the biology of chromatin and chromosomes in both plants and animals, and to publish them as rapidly as possible. In consultation with the associate editors, we have changed the cover design and have revised the subtitle and the Aims and Scope statement so that they broaden the journal's appeal to include findings on chromatin, chromosomes, and genomes in plants and animals that relate to disease states. Both of these changes are evident on the front cover and flyleaf of this Chromosome Research issue, the first of volume 21 (2013).

I value and am comfortable with the journal's organizational structure that Herbert and his cofounders established: most of the papers submitted that fall within the journal's aim and scope are efficiently handled by one of our highly respected associate editors, all of whom are fair individuals with areas of expertise that, in conjunction with our Editorial Advisory Board, cover the multiple avenues of chromosome biology reflected in the journal pages. Like Herbert, I view our board as members of a team in which all are vital to the success of the journal, and I will continue to seek their input on a routine basis.

The primary Wikipedia definition of an academic scientific journal is as "a periodical publication intended to further the progress of science, usually by reporting new research." In the past, Chromosome Research, like many other scholarly journals, used some of its pages as a forum for reporting news and events related to chromatin, chromosomes, and the people that study them: from book reviews and the highlights of scientific meetings to obituaries and editorials. This gave our journal an "identity" largely shaped by Herbert's influence. Chromosome Research is now accessed almost exclusively online, and due to time constraints, most researchers go regularly to an abstracting service to identify and download the latest papers published in their field, which they then (maybe) read and file without even having seen the journal's home page. This behavioral change, from browsing a journal hardcopy to downloading specific individual papers, has catalyzed the genesis and expansion of new Society-based and OA journals that publish many thousands of papers per year. In an attempt to re-establish a tangible identity, we have started a LinkedIn group in which news, questions, editorials, and other ideas and comments related to the biology of chromatin and chromosomes (http:// www.linkedin.com/groups/ChromosomeResearch3447426) can be shared in real time. This group is currently $350+$ strong, and I encourage those of you reading this to join and contribute.

Although I am not a fan of metrics, as an Editor-inChief, they become more important considerations. Thomson's Journal Citation Report has Chromosome Research listed in two categories: Genetics \& Heredity and also Biochemistry \& Molecular Biology. One of Herbert's hopes before he retired was to see our impact factor, which has hovered between 3.2 and 3.4 over the past few years, to hit 4.0. Certainly, this is a worthy goal for the future. Our current impact factor puts us in the top $40 \%$ of both subject matter categories, which is very respectable for a (non-general) niche journal. Our Eigenfactor Article Influence Score of 1.518 places us in the top $25 \%$ of the Genetics \& Heredity and Biochemistry \& Molecular Biology journals, meaning that the influence of each article published in Chromosome Research is well above average. These metrics reflect the high scientific standards set by the Editorial Board which I will do my utmost to maintain. Of the last 370 papers submitted to the journal, only $38 \%$ (140) were accepted for publication. Some were rejected not for scientific reasons, but because the work did not fall within the aims and scope of our journal, which would indicate that the journal enjoys a good reputation outside the field of chromosome biology.

Springer's journal website, www.chromosome research.net, is where all the journal content, dating back to volume 1 issue 1 , can be found and which in turn links to the Springer catalog page. Here, you can find all kinds of information about the journal including direct links to recent special issues. We are also working with Springer to institute a formal pre-submission inquiry mechanism so that authors can rapidly determine whether their work will at least be reviewed by the journal.

Finally, the topic of OA is one that Herbert and I studied and debated in considerable detail, frequently in consultation with one of the world's leading experts. Chromosome Research is currently published under a hybrid subscription model: all papers are published without charging any costs, not even for color, to authors, and access is then through subscription. However, all articles in our highly successful special "themed" issues are published at no cost to the authors 
and are made freely accessible by the publisher. Moreover, authors whose funding agencies or institutes have an open access mandate may select the open choice option following acceptance in order to meet this requirement. This model proves attractive since it meets the best of both worlds.
My sincere thanks go once again to Herbert, and I wish him good health in his retirement. I look forward to interacting with you in the coming years, and I wish you all good health and happiness for the holiday season.

Conly L. Rieder

December 2012 